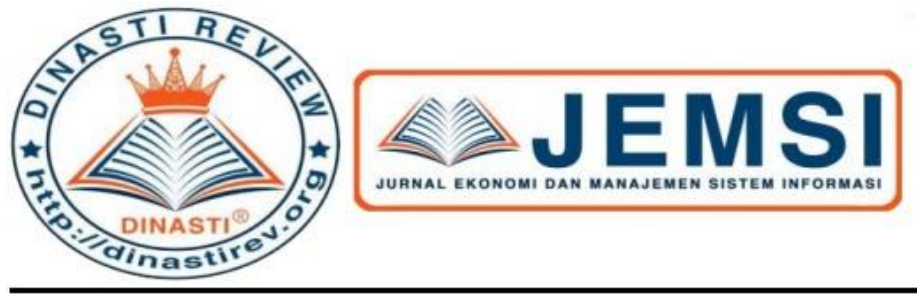

$+62878-9658-6407$

087896586407 ()

https://dinastirev.org/JEMSI (-)

editor@dinastirev.org (G.)

\title{
PENGARUH PENGETAHUAN PERPAJAKAN, KESADARAN WAJIB PAJAK, TINGKAT PENDIDIKAN DAN SOSIALISASI PERPAJAKAN TERHADAP KEPATUHAN WAJIB PAJAK PADA UMKM DIKOTA PADANG
}

Yosi Yulia ${ }^{1)}$, Ronni Andri Wijaya ${ }^{2)}$, Desi Permata Sari ${ }^{3)}$ M. Adawi ${ }^{4)}$

${ }^{1,2,3,4)}$ Fakultas Ekonomi dan Bisnis Universitas Putra Indonesia "YPTK" Padang

\begin{tabular}{|c|c|}
\hline $\begin{array}{l}\text { ARTICLE INFORMATION } \\
\text { Received: 20 Februari } 2020 \\
\text { Revised: } 28 \text { Februari } 2020 \\
\text { Issued: } 7 \text { Maret } 2020 \\
\text { Corresponding author: } \\
\text { Yosi Yulia } \\
\text { E-mail : } \\
\text { Yosiyulia.upiyptk@gmail.com } \\
\text { DOI:10.31933/JEMSI }\end{array}$ & $\begin{array}{l}\text { Abstrak: Penelitian ini bertujuan untuk menguji } \\
\text { seberapa besar pengaruh pengaruh pengetahuan } \\
\text { perpajakan, kesadaran wajib pajak, tingkat pendidikan } \\
\text { dan sosialisasi perpajakan terhadap kepatuhan wajib } \\
\text { pajak. Penelitian ini mengambil jumlah sampel } \\
\text { sebanyak } 93 \text { responden yang berasal dai UMKM Kota } \\
\text { Padang Kec Lubug Begalung. Hasil analisis ini } \\
\text { menunjukkan bahwa secara simultan pengetahuan } \\
\text { perpajakan, kesadaran wajib pajak, tingkat pendidikan } \\
\text { dan sosialisasi perpajakan berpengaruh terhadap } \\
\text { kepatuhan wajib pajak. Secara parsial kesadaran wajib } \\
\text { pajak berpengaruh terhadap kepatuhan wajib pajak. } \\
\text { Pengetahuan perpajakan, tingkat pendidikan dan } \\
\text { sosialisasi perpajakan tidak berpengaruh secara parsial } \\
\text { terhadap kepatuhan wajib pajak. } \\
\text { Kata Kunci: Pengetahuan Perpajakan, Kesadaran } \\
\text { Wajib Pajak, Tingkat Pendidikan, Sosialisasi } \\
\text { Perpajakan, Kepatuhan Wajib Pajak }\end{array}$ \\
\hline
\end{tabular}

\section{PENDAHULUAN}

Indonesia merupakan salah satu negara berkembang di dunia yang selalu melakukan pembangunan dari segala sektor. Hal ini demi terciptanya masyarakat yang sejahtera contohnya memberikan pelayanan kepada masyarakat, penegakan hukum yang adil serta memelihara keamanan dan ketertiban negara. Biaya yang dibutuhkan untuk memenuhi kebutuhan ini tentunya tidak sedikit, adapun upaya memenuhi kepentingan negara guna menciptakan pertumbuhan ekonomi. Pajak merupakan salah satu iuran yang diberikan kepada negara yang bersifat terhutang oleh yang wajib membayarnya, menurut peraturan perundangundangan dengan tidak mendapatkan manfaat dari pajak secara langsung, dengan tujuan untuk membiayai pengeluaran umum yang berhubungan dengan tugas negara.

Persoalan kepatuhan perpajakan di Indonesia menjadi sangat penting karena jika wajib pajak tidak patuh maka dapat menimbulkan keinginan untuk melakukan tindakan penghindaran, pengelakan dan pelalaian pajak yang pada akhirnya akan merugikan negara 
yaitu kurangnya penerimaan pajak penghasilan dari wajib pajak sebagai kewajibannya yang semestinya patuh dan menjalankan kewajiban sebagai warga Indonesia yang baik. Kasuskasus pajak yang terjadi belakangan ini di Indonesia membuat masyarakat dan wajib pajak resah dan khawatir untuk membayar pajak.

\section{KAJIAN PUSTAKA \\ Kepatuhan Wajib Pajak}

Menurut Arisandy (2017: 65), kepatuhan pajak adalah suatu keadaan dimana Wajib Pajak memenuhi semua kewajiban perpajakan dan melaksanakan hak perpajakannya. Kepatuhan wajib pajak dibentuk oleh dimensi pemeriksaan wajib pajak, penegakan hukum, dan kompensasi pajak. Undang-Undang No. 28 Tahun 2007 Pasal 4 ayat (1) menyatakan wajib pajak wajib mengisi dan menyampaikan surat pemberitahuan dengan benar, lengkap, jelas, dan menandatanganinya.

\section{Pengetahuan Perpajakan}

Menurut Wijayanti dkk, (2015:311) Pengetahuan perpajakan adalah suatu proses dimana wajib pajak memahami dan mengetahui tentang peraturan dan Undang-Undang serta tata cara perpajakan dan menerapkannya untuk melakukan kegiatan perpajakan seperti, membayar pajak, melaporkan SPT, dan sebagainya. Jika seseorang telah memahami dan mengerti tentang perpajakan maka akan terjadi peningkatan pada kepatuhan wajib pajak.

\section{Kesadaran Wajib Pajak}

Menurut Wardani dan Rumiyatun (2017:17) kesadaran wajib pajak adalah tindakan itikad baik seseorang untuk memenuhi kewajiban membayar pajak berdasarkan hati nuraninya yang tulus ikhlas. Semakin tinggi tingkat kesadaran wajib pajak, maka pemahaman dan pelaksanaan kewajiban perpajakan semakin baik sehingga dapat meningkatkan kepatuhan.

\section{Tingkat Pendidikan}

Menurut Rahman (2018:6) menjelaskan pendidikan pada dasarnya merupakan usaha pengembangan sumber daya manusia yang dilakukan secara sistematis, pragmatis, dan berjenjang agar menghasilkan manusia-manusia yang berkualitas yang dapat memberikan manfaat dan sekaligus meningkatkan harkat dan martabatnya.

\section{Sosialisasi perpajakan}

Syafiqurrahman (2016:68) sosialisasi perpajakan dilakukan kepada wajib pajak secara tidak langsung selalu memberikan pengaruh dalam meningkatnya pengetahuan perpajakan wajib pajak, walaupun tujuan sosialisasi perpajakan yang sebenarnya adalah untuk meningkatkan kepatuhan perpajakan. Oleh karena itu, penelitian tentang kepatuhan perpajakan dengan mengkaitkan sosialisasi perpajakan dan pengetahuan perpajakan sabagai variabel yang saling mempengaruhi sangat penting untuk dianalisis.

\section{METODE PENELITIAN}

Pada penelitian ini penulis mengambil lokasi penelitian di wilayah Kota Padang, Kecamatan Lubuk Begalung, Khususnya yang terdaftar pada Dinas Koperasi dan UMKM 
Kota Padang. Sampel yang digunakan sebanyak 93 UMKM setalh dilakukan dengan rumus slovin. Dalam penelitian ini adalah menggunakan pendekatan kuantitatif. Analisis data yang terdiri dari uji hipotesis Uji $\mathrm{T}$ dan Uji F dan Koefisien Determinasi $\left(\mathrm{R}^{2}\right)$. Metode dalam penelitian ini menggunakan dengan menggunakan SPSS Versi 23.

\section{HASIL DAN PEMBAHASAN}

\section{Pengujian Hipotesis Secara Parsial ( Uji-t)}

Analisis regresi berganda digunakan untuk menentukan seberapa besar pengaruh variabel independen terhadap variabel dependennya. Pada penelitian ini dapat digunakan teknik regresi berganda dengan bantuan program SPSS 23

Table 1 : Hasil Uji Hipotesis Uji T Coefficients $^{\mathrm{a}}$

\begin{tabular}{|c|c|c|c|c|c|c|}
\hline \multirow{2}{*}{\multicolumn{2}{|c|}{ Model }} & \multicolumn{2}{|c|}{$\begin{array}{l}\text { Unstandardized } \\
\text { Coefficients }\end{array}$} & \multirow{2}{*}{\begin{tabular}{|l}
$\begin{array}{l}\text { Standardize } \\
\text { d } \\
\text { Coefficients }\end{array}$ \\
Beta
\end{tabular}} & \multirow[b]{2}{*}{$\mathrm{T}$} & \multirow[b]{2}{*}{ Sig. } \\
\hline & & B & Std. Error & & & \\
\hline \multirow[t]{5}{*}{1} & (Constant) & 4,119 & 2,352 & & 1,786 & ,078 \\
\hline & PP & ,035 &, 104 & ,028 & ,336 & ,738 \\
\hline & KSWP & ,733 & ,087 & ,704 & 8,448 &, 000 \\
\hline & $\mathrm{TP}$ & ,038 &, 120 & ,031 & ,315 & ,753 \\
\hline & SP &, 020 &, 071 &, 025 & ,285 & ,776 \\
\hline
\end{tabular}

Berdasarkan table 1 diatas pengaruh variabel pengetahuan Pemahaman Pajak, dan Sanksi Pajak dapat diuji sebagai berikut:

1. Pengujian koefisien regresi variabel pengetahuan perpajakan terhadap kepatuhan wajib pajak $\left(\mathrm{X}_{1}\right)$

Hasil pengujian uji t menunjukkan bahwa variabel pengetahuan perpajakan diperoleh $t_{\text {hitung }}$ sebesar 0,336 dan $t_{\text {tabel }}$ sebesar 1,98729 yaitu $(0,336<1,98729)$, dengan tingkat signifikansi 0,738>0,05. Maka, dapat disimpulkan Ho Diterima dan $\mathrm{H}_{1}$ Ditolak. Artinya pengetahuan perpajakan secara parsial tidak berpengaruh signifikan terhadap kepatuhan wajib pajak.

2. Pengujian koefisien regresi variabel kesadaran wajib pajak terhadap kepatuhan wajib pajak $\left(\mathrm{X}_{2}\right)$

Hasil pengujian uji t menunjukkan bahwa variabel kesadaran wajib pajak diperoleh $\mathrm{t}_{\text {hitung }}$ sebesar 8,448 dan $\mathrm{t}_{\text {tabel }}$ sebesar 1,98729 yaitu $(0,422<1,98729)$, dengan tingkat signifikansi $0,000<0,05$, Sehingga dapat disimpulkan Ho Ditolak dan $\mathrm{H}_{2}$ Diterima. Artinya kesadaran wajib pajak secara parsial berpengaruh positif dan signifikan terhadap kepatuhan wajib pajak. 
3. Pengujian koefisien regresi variabel tingkat pendidikan terhadap kepatuhan wajib pajak $\left(\mathrm{X}_{3}\right)$

Hasil pengujian uji t menunjukkan bahwa variabel tingkat pendidikan diperoleh $\mathrm{t}_{\mathrm{hitung}}$ sebesar 0,315 dan $t_{\text {tabel }}$ sebesar 1,98729 yaitu $(0,315<1,98729)$, dengan tingkat signifikansi 0,753 > 0,05. Maka, dapat disimpulkan Ho Diterima dan $\mathrm{H}_{3}$ Ditolak. Artinya tingkat pendidikan secara parsial tidak berpengaruh signifikan terhadap kepatuhan wajib pajak.

4. Pengujian koefisien regresi variabel sosialisasi perpajakan terhadap kepatuhan wajib pajak $\left(\mathrm{X}_{4}\right)$

Hasil pengujian uji t menunjukkan bahwa variabel sosialisasi perpajakan diperoleh $t_{\text {hitung }}$ sebesar 0,285 dan $t_{\text {tabel }}$ sebesar 1,98729 yaitu $(0,285<1,98729)$, dengan tingkat signifikansi 0,776 > 0,05. Maka, dapat disimpulkan Ho Diterima dan $\mathrm{H}_{4}$ Ditolak. Artinya sosialisasi perpajakan secara parsial tidak berpengaruh signifikan terhadap kepatuhan wjib pajak .

\section{Pengujian Hipotesis Secara Bersama-Sama ( Uji-F)}

Tabel 2: Pengujian Hipotesis Secara Bersama-Sama (Uji F)

\begin{tabular}{|rl|r|r|r|r|l|}
\hline \multicolumn{2}{|l|}{ Model } & $\begin{array}{l}\text { Sum of } \\
\text { Squares }\end{array}$ & Df & Mean Square & F & Sig. \\
\hline $1 \quad$ Regression & 840,806 & 4 & 210,202 & 26,278 &, $000^{\text {b }}$ \\
& Residual & 703,925 & 88 & 7,999 & & \\
& Total & 1544,731 & 92 & & & \\
\hline
\end{tabular}

Sumber : data primer (diolah)

Dari tabel 2 di atas dapat dilihat pengujian ini dilakukan dengan cara membandingkan nilai $\mathrm{F}_{\text {hitung }}$ dengan $\mathrm{F}_{\text {tabel }}$ karena nilai $\mathrm{F}_{\text {hitung }}$ lebih besar dari nilai $\mathrm{F}_{\text {tabel }}(26,278>2,81)$ dengan tingkat signifikan 0,000 lebih kecil dari 5\%. Maka diperoleh $\mathrm{H}_{\mathrm{o}}$ ditolak dan $\mathrm{H}_{4}$ diterima, yang berarti hal ini dilakukan secara bersama-sama antara pengetahuan perpajakan, kesadaran wajib pajak, tingkat pendidikan dan sosialisasi perpajakan terhadap kepatuhan wajib pajak.

\section{Koefisien Determinasi $\left(\mathbf{R}^{2}\right)$}

Tabel 3: Hasil Pengujian Determinasi

\begin{tabular}{|l|r|r|r|r|}
\hline Model & $\mathrm{R}$ & R Square & Adjusted R Square & $\begin{array}{c}\text { Std. Error of the } \\
\text { Estimate }\end{array}$ \\
\hline 1 &, $738^{\mathrm{a}}$ &, 544 &, 524 & 2,228 \\
\hline
\end{tabular}

Sumber : data primer (diolah)

Berdasarkan tabel 3 diatas diperoleh angka Adjusted R Square sebesar 0,524 hal ini menunjukan bahwa sumbangan variabel pengetahuan perpajakan, kesadaran wajib pajak, 
tingkat pendidikan dan sosialisasi perpajakan sebesar 0,524 atau 52.7\% sedangkan sisanya sebesar $47,6 \%$ di pengaruhi variabel lain.

\section{Pembahasan}

Dari hasil penelitian yang sudah dijabarkan sebelumnya bahwa pengetahuan perpajakan tidak berpengaruh dan signifikan terhadap kepatuhan wajib pajak pada UMKM di kota Padang. Hal ini menunjukan bahwa pengetahuan akan pentingnya membayar pajak harus dimiliki setiap pemilik UMKM yang ada di kota Padang agar kepatuhan wajib pajak dapat terealisasikan. Penelitian ini sejalan dengan yang dilakukan oleh Saryadi (2019) bahwa pengetahuan perpajakan tidak berpengaruh signifikan terhadap kepatuhan wajib pajak. Kesadaran wajib pajak berpengaruh positif dan signifikan terhadap kepatuhan wajib pajak pada UMKM di kota Padang. Hal ini menunjukan bahwa tingkat kesadaran wajib pajak UMKM di kota Padang dalam memenuhi kepatuhan wajib pajaknya dalam kategori baik, dan mereka menganggap membayar pajak merupakan cara mengabdi pada pemerintah. Penelitian ini sejalan dilakukan oleh Merianto (2017) bahwa kesadaran wajib pajak berpengaruh signifikan terhadap kepatuhan wajib pajak. Tingkat pendidikan tidak berpengaruh signifikan terhadap kepatuhan wajib pajak pada UMKM di kota Padang. Hal ini menunjukan bahwa tingkat pendidikan UMKM dikota Padang masih rendah, yang menyebabkan para pihak UMKM dikota Padang belum maksimal dalam pembayaran pajaknya. Penelitian ini sejalan dengan yang dilakukan oleh Rahman (2018) bahwa tingkat pendidikan tidak berpengaruh terhadap kepatuhan wajib pajak. sosialisasi perpajakan tidak berpengaruh signifikan terhadap kepatuhan wajib pajak pada UMKM di kota Padang. Penelitian ini dilakukan oleh Mahadianto dan Astuti (2017) bahwa sosialisasi perpajakan tidak berpengaruh signifikan terhadap kepatuhan wajib pajak.

\section{KESIMPULAN DAN SARAN}

Dari hasil pengujian yang dilakukan, maka dapat disimpulkan sebagai berikut : Hasil analisis ini menunjukkan bahwa secara simultan pengetahuan perpajakan, kesadaran wajib pajak, tingkat pendidikan dan sosialisasi perpajakan berpengaruh terhadap kepatuhan wajib pajak. Secara parsial kesadaran wajib pajak berpengaruh terhadap kepatuhan wajib pajak. Pengetahuan perpajakan, tingkat pendidikan dan sosialisasi perpajakan tidak berpengaruh secara parsial terhadap kepatuhan wajib pajak.

\section{DAFTAR RUJUKAN}

Arisandy, Nelsi. (2017). Pengaruh pemahaman wajib pajak, kesadaran wajib pajak dan sanksi pajak terhadap kepatuhan wajib pajak orang pribadi yang melakukan kegiatan bisnis online di pecan baru. Jurnal Ilmiah Ekonomi dan Bisnis. Vol (14). 62-71.

Merianto dan Asfa, (2017), Pengaruh Sanksi Perpajakan, Pelayanan Fiskus, Pengetahuan Dan Pemahaman Perpajakan, Kesadaran Perpajakan Terhadap Kepatuhan Wajib Pajak. Jurnal Akuntansi Vol (6). 1-13

Rahman, Arif, (2018). Pengaruh Kesadaran Wajib Pajak, Tingkat Pendidikan, Dan Pendapatan Terhadap Kepatuhan Membayar Pajak Bumi Dan Bangunan. Akuntansi Dewantara. Vol (1). 1-19

Saryadi, Saridan, (2019). Pengaruh Sosialisasi Perpajakan dan Pengetahuan Perpajakan, Terhadap Kepatuhan Wajib Pajak. Akuntansi Dewantara. Vol (1). 17-27

Syafiqurrahman, (2016). Pengaruh Sosialisasi Perpajakan Terhadap Kepatuhan Wajib Pajak Orang Pribadi Pada Kantor Pelayanan Pajak Pratama Lampung. Jurnal Ekonomi dan Akutansi. Vol (3). 24-36 
Wardani dan Rumiyatun. (2017). Pengaruh Sosialisasi Perpajakan Terhadap Kepatuhan Wajib Pajak Dengan Pengetahuan Perpajakan Sebagai Variabel Intervening. Jurnal Nominal. Vol (7). 33-54.

Wijayanti, Rahayu. (2015). Pengaruh Pemahaman, Sanksi Perpajakan, Tingkat Kepercayaan pada Pemenrintah dan Hukum terhadap Kepatuhan Dlaa Membayar Wajib Pajak Peran Profesi Akuntansi. Vol (16). 306-327 